\title{
Analysis Image-Based Automated 3D Crack Detection for Post-disaster Bridge Assessment in Flyover Mall Boemi Kedaton
}

\author{
Muhammad Abi Berkah Nadi ${ }^{1}$, Sayed Ahmad Fauzan ${ }^{1}$ \\ ${ }^{1}$ Civil Engineering Department, Institut Teknologi Sumatera, South Lampung, Lampung Province, Indonesia.
}

\begin{abstract}
Recovery efforts following a disaster can be slow and painstaking work, and potentially put responders in harm's way. A system which helps identify defects in critical building elements (e.g., concrete columns) before responders must enter a structure can save lives. In this paper we propose a system, centered around an image based three-dimensional (3D) reconstruction method and a new $3 D$ crack detection algorithm. The image-based method is capable of detecting and analyzing surface damages in $3 D$. We also demonstrate how the robotics can be used to gather the images from which the reconstruction is created, further reducing the risk to responders. In this regard, image-based $3 D$ reconstructions represent a convenient method of creating $3 D$ models because most robotic platforms can carry a lightweight camera payload. Additionally, the proposed $3 D$ crack detection algorithm also provides the advantage of being able to operate on $3 D$ mesh models regardless of their data collection source. Our experimental results show that $3 D$ crack detection algorithm performs well constructions, successfully identifying cracks, reconstructing $3 D$ profiles, and measuring geometrical characteristics on damaged elements and not finding any cracks on intact ones.
\end{abstract}

\section{Introduction}

Inspecting and managing transportation infrastructure, considering the heavy usage of these systems, pose significant challenges to engineers and owners. The National Bridge Inspection Standards (NBIS) mandate that road bridges carrying passenger vehicles must receive a routine inspection every two years (Ryan, Mann, Chill, \& Ott, 2012). The specifics of the inspection requirements vary based on structure type, materials and location, among many parameters. In most cases, these inspections are primarily visual and require hands-on observations in order to check for loose and broken hardware, spalling, corrosion, crushing, delamination, insect damage and a multitude of other maintenance and safety issues (Jahanshahi, Kelly, Masri, \& Sukhatme, 2009).

In this topic took a case study of the Teuku Umar road - ZA Pagar Alam (Mall Boemi Kedaton) because on the road there are flyover buildings and on this road that serves to increase the traffic volume on this road. This is done to do the detection analysis again. In this study, the modeling is to optimize the acquisition and processing parameters to detect cracks well. By taking a photo field, you can find the intersection between the camera orientation lines that pass through the camera center and the photo field. The distance between this crossing point and the camera center is calculated as the distance traveled. 


\section{Technique}

\subsection{Interferometric synthetic-aperture radar (InSAR)}

Interferometric synthetic aperture radar, abbreviated InSAR (or deprecated IfSAR), is a radar technique used in geodesy and remote sensing. This geodetic method uses two or more synthetic aperture radar (SAR) images to generate maps of surface deformation or digital elevation, using differences in the phase of the waves returning to the satellite or aircraft. The technique can potentially measure millimetre-scale changes in deformation over spans of days to years. It has applications for geophysical monitoring of natural hazards, for example earthquakes, volcanoes and landslides, and in structural engineering, in particular monitoring of subsidence and structural stability.

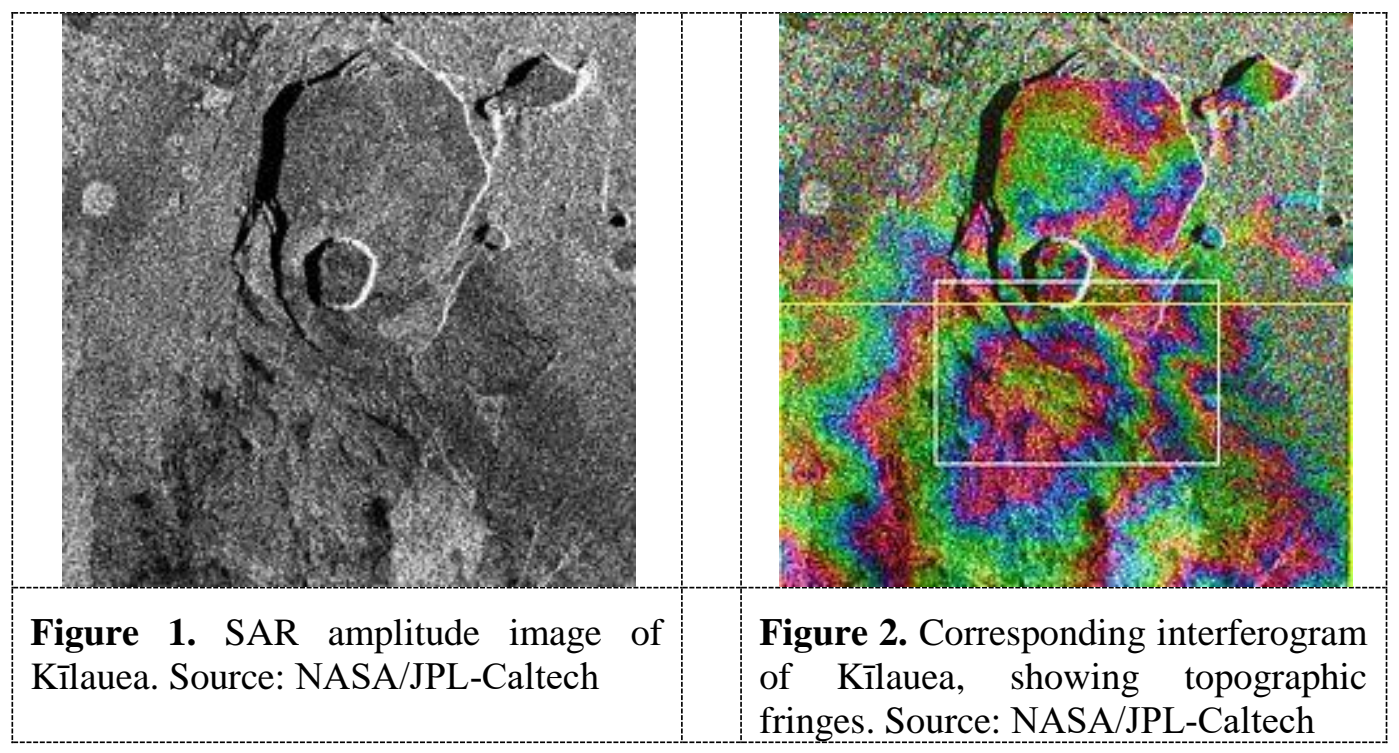

Data acquired on April 13, 1994 and on October 4, 1994 from the X-band Synthetic Aperture Radar on board the space shuttle Endeavour were used to generate interferometric fringes, which were overlaid on the X-SAR image of Kilauea. The volcano is centered in this image at 19.58 degrees north latitude and 155.55 degrees west longitude. The image covers about 9 kilometers by 13 kilometers (5.6 miles by 8 miles). The X-band fringes correspond clearly to the expected topographic image. The yellow line indicates the area below which was used for the three-dimensional image using altitude lines. The yellow rectangular frame fences the area for the final topographic image.

\subsection{Phase}

SAR makes use of the amplitude and the absolute phase of the return signal data. In contrast, interferometry uses differential phase of the reflected radiation, either from multiple passes along the same trajectory and/or from multiple displaced phase centers (antennas) on a single pass. Since the outgoing wave is produced by the satellite, the phase is known, and can be compared to the phase of the return signal. The phase of the return wave depends on the distance to the ground, since the path length to the ground and back will consist of a number of whole wavelengths plus some fraction of a wavelength. In practice, the phase of the return signal is affected by several factors, which together can make the absolute phase return in any SAR data collection essentially arbitrary, with no correlation from pixel to pixel. To get any useful information from the phase, some of these effects must be isolated and removed. Interferometry uses two images of the same area taken from the same position (or, for topographic applications, slightly different positions) and finds the difference in phase between them, producing an image known as an interferogram. 


\subsection{Automated Crack Detection}

Following a disaster, the detection of structural defects in a building is critical to determining its integrity and usability. Crack detection is an effective means of identifying these defects, and if a robotic system can identify structural cracks inside a building before humans must enter, the safety of USAR operations is greatly enhanced (Golparvar-Fard et al. 2010). There are a variety of different crack detection techniques that exist for various materials. Some of the previous research benefits from application of a laser scanner. Despite the benefits, a laser scanner is an expensive, heavy device which can significantly increase the payload on a robot. In addition it requires significant power for operation and may require several markers for registration of the scanned point cloud. Although laser scanners are continuously getting smaller and their cost is dropping, but because of these limitations, their application at this stage may not yet be very attractive. In contrast, in the last few years several research groups have proposed the use of image-based approaches for condition assessment of civil infrastructure systems and in particular crack detection.

These methods benefit from various image processing techniques such as edge and corner detection, point-based feature detection and extraction, and template matching techniques to conduct identification of the surface anomalies. Some of these techniques such as Sinha et al. (2003) are also accompanied with machine learning techniques such as neuro-fuzzy networks for precise classification purposes. An example of a template matching approach by Ehrig et al. (2011) is presented in Fig. 2. This involves passing a much smaller template image over the larger detection image at various angles and subtracting the two. If that result at a given position is a small enough value the target feature from the template (i.e., a crack) has been located.
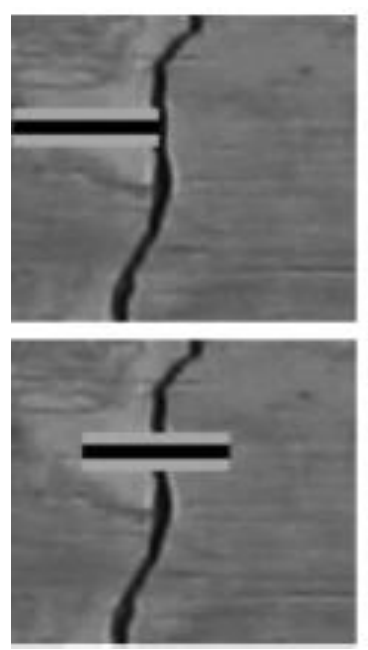
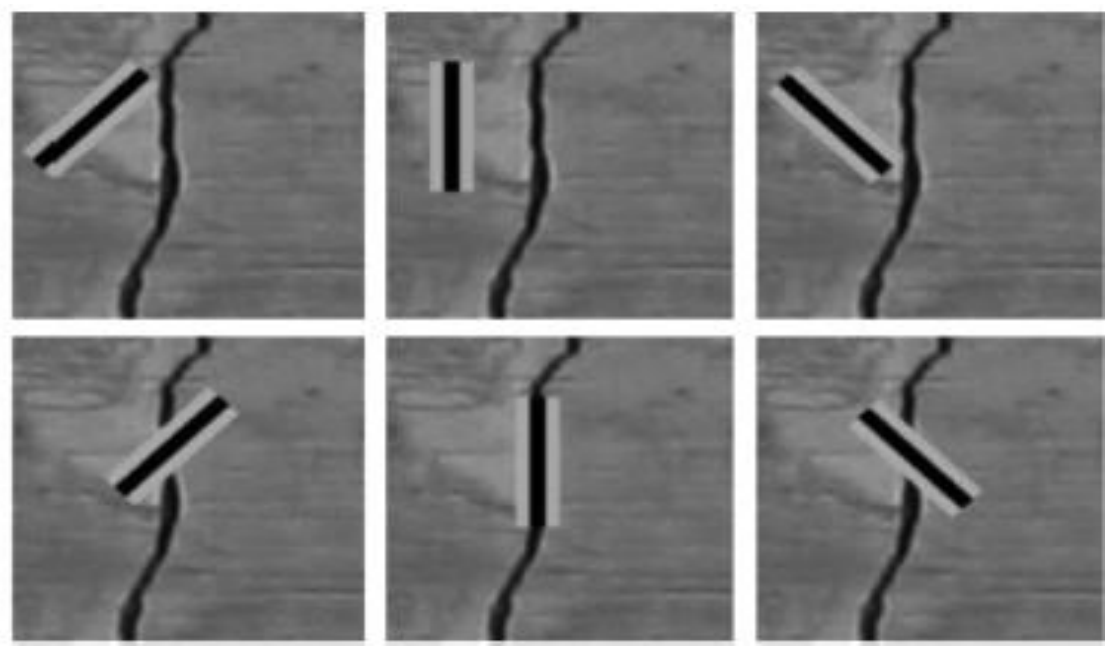

Figure 4. An example of template matching for crack detection

In Fig. 4, the crack would be detected in the $8^{\text {th }}$ image in the series, where the template is aligned with the crack. Despite their benefits, template matching and majority of the other 2D approaches discussed previously do not provide 3D depth information directly from the content of the images and as a result do not enable measurement of severity of these cracks. More comprehensive review of the 2D condition assessment and in particular crack detection methods can be found in "Adaptive visionbased crack detection using 3D scene reconstruction for condition assessment of structures" (Jahanshahi et al. 2009; Brilakis et al. 2011; Jahanshahi and Masri 2013). 


\section{Methods}

\subsection{Evaluative metrics}

The results of the inspection were evaluated in a variety of ways, both qualitative and quantitative. During the construction of the bridge, fabrication and construction errors initiated a series of minor defects in the bridge. These defects were identified early on in the process as representative of the kinds of details that must be tracked and assessed during the NBIS inspection process. In this work, they were used to provide illustrative and qualitative assessments of the capabilities of the CRP-based inspection approach to capture and represent structural details with sufficient accuracy for NBIS purposes.

In order to efficiently determine the local nearest neighbours for every point in the data-set, the space partitioning method called $k-d$ trees was applied to the well-known $k$-Nearest Neighbours $(k$-NN) algorithm to reduce the search complexity. Utilising $k-\mathrm{NN}$ rather than a Fixed Distance Neighbourhood (FDN) avoided the problem of point density variation within point clouds (Hoppe, DeRose, Duchamp, McDonald, \& Stuetzle, 1992). For the $k$ points that form the neighbourhood of a $3 \mathrm{D}$ point $\mathrm{pi}$ in a point cloud, the covariance matrix, $\mathbf{C}$, is defined as (Jolliffe, 2002):

$$
\mathrm{C}_{3 \times 3}=\frac{1}{k} \sum_{i=1}^{k}\left(\mathrm{p}_{\mathrm{i}}-\bar{p}\right)\left(\mathrm{p}_{\mathrm{i}}-\bar{p}\right)^{T} ; \bar{p}=\frac{1}{k} \sum_{i=1}^{k} p_{i}
$$

Where $\overline{\mathrm{p}}$ is the local data centroid (arithmetic mean) within pi's neighbourhood (Npi). However, due to imperfect correspondence between point cloud 3D points, higher local laundry will consequently be formulated into the Final Model in a multiple-scan registration process.

\subsection{Crack Detection}

The analysis of cracks and other surface damages in 3D can provide an additional layer of information that previously was not available for condition assessment purposes. A summary of the current crack detection methods reviewed and the contribution of this paper is presented in Table 1.

Table 1. Matrix of Current Crack Detection Methods

\begin{tabular}{|c|c|c|c|c|c|}
\hline \multirow{2}{*}{$\begin{array}{c}\text { Detection } \\
\text { method/ } \\
\text { data } \\
\text { source }\end{array}$} & \multicolumn{5}{|c|}{ Demonstrated location } \\
\hline & Roadway asphalt & $\begin{array}{l}\text { Bridge } \\
\text { structure }\end{array}$ & $\begin{array}{l}\text { Building elements and } \\
\text { various concrete surfaces/blocks }\end{array}$ & $\begin{array}{l}\text { Underground } \\
\text { piping }\end{array}$ & Tunnel \\
\hline 2D image & $\begin{array}{l}\text { Abe et al. (1992, 1993), } \\
\text { Ahmed et al. (2011), } \\
\text { Taso et al. (1994), } \\
\text { Kaseko et al. (1994), } \\
\text { Wang et al. (1998), Kim } \\
\text { and } \\
\text { Haas (2002), Saar and } \\
\text { Talvik (2010), Koch and } \\
\text { Brilakis (2011), } \\
\text { Koch et al. (2013) }\end{array}$ & $\begin{array}{l}\text { Abdel- } \\
\text { Qader } \\
\text { et al. (2006), } \\
\text { Oh et al. } \\
(2009)\end{array}$ & $\begin{array}{l}\text { Chen et al. (2006), Yamaguchi and } \\
\text { Hashimoto (2006, 2009), } \\
\text { Kabir et al. (2009), Fujita and } \\
\text { Hamamoto (2009), Zhu and } \\
\text { Brilakis (2010), } \\
\text { Lee et al. (2013), Brilakis et al. } \\
\text { (2011), } \\
\text { Zhang et al. (2011), Zhu et al. } \\
\text { (2011), } \\
\text { German et al. (2012), Jahanshahi } \\
\text { and } \\
\text { Masri (2012), Jahanshahi and } \\
\text { Masri (2013), } \\
\text { German et al. (2013) }\end{array}$ & $\begin{array}{l}\text { Sinha et al. } \\
(2003) \text {, } \\
\text { Sinha and } \\
\text { Fieguth } \\
(2006) \text {, } \\
\text { Guo et al. } \\
(2009)\end{array}$ & $\begin{array}{l}\text { Yu et al. } \\
(2007)\end{array}$ \\
\hline $2 \mathrm{D}+3 \mathrm{D}$ & Jog et al. (2012) & - & - & - & \\
\hline 3D image & - & - & The focus of this paper & - & \\
\hline 3D depth & $\begin{array}{l}\text { Jahanshahi et al. } \\
(2013 a, b)\end{array}$ & - & $x_{1}+x_{1}$ & - & \\
\hline
\end{tabular}




\subsection{Small-Scale Validation}

The first step in validating the crack detection algorithm was to create a controlled, small-scale test setup with a cracked object to reconstruct. Image-based 3D reconstructions had successfully been created from 48,640 $\times 480$ pixel images taken at a distance of $60 \mathrm{~cm}$ around small objects. Therefore, a cinder block of $20 \mathrm{~cm}$ square with a three to four $\mathrm{cm}$ wide horizontal crack extending across one side was used as the target object to reconstruct with those parameters. The cinder block also has the advantage of being a commonly used building material, enhancing the realism of the initial test.

Table 2. The Pseudo Code of the Proposed Algorithm

\begin{tabular}{cl}
\hline Step & \multicolumn{1}{c}{ Procedure } \\
\hline 1 & Load all mesh face elements (3, 3D points per element) \\
2 & Examine a face element \\
3 & Compute its surface normal (from 2 vectors connecting the 3 points) \\
4 & Compare its normal to the ground plane/axial direction (angle $\beta$ ) \\
5 & If $|90-\beta|>$ threshold (e.g., $15^{\circ}$ ) \\
6 & Mark as cracked (tint red) \\
7 & Else \\
8 & Mark as uncracked (tint green) \\
9 & End If \\
10 & Move to next face element \\
11 & Save all tinted elements \\
\hline
\end{tabular}

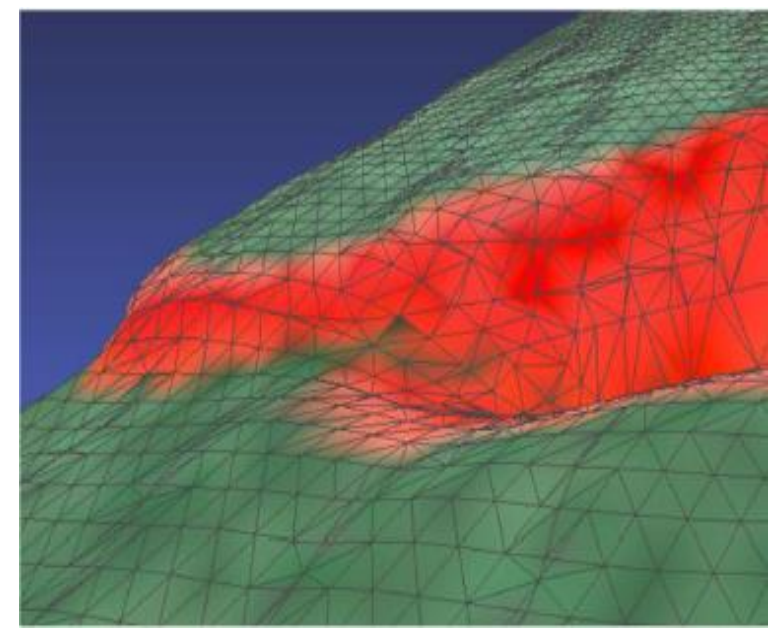

Figure 5. Close-up of a color-coded 3D model, showing individual mesh element triangles and a cracked area clearly indicated with reddish (darker) hues

Once the images were collected they were processed using the pipeline shown in Fig. 5. Because the camera was shooting from near ground level, the top and bottom of the block were not visible and were not reconstructed. These areas were filled in during meshing because of the Poisson reconstruction method and were removed fromthe models during trimming. The CDA threshold used for all models in this section was $20^{\circ}$.

As can be clearly seen in Fig. 5, the crack detection algorithm successfully identified the horizontal gash in the center of the cinder block and color-coded it with a red tint (some small indents at the top and bottom of the model were also found). The algorithm reported the model's surface completeness to be $100 \%$, and its cracked area to be $2.75 \%$. This result was very encouraging and larger tests were pursued. 
ICOSITER 2018 Proceeding Journal of Science and Applicative Technology

\subsection{Focus of This Study}

Case study of the Teuku Umar road - ZA Pagar Alam (Mall Boemi Kedaton) because on the road there are flyover buildings and on this road that serves to increase the traffic volume on this road. In this study, the modeling is to optimize the acquisition and processing parameters to detect cracks well.

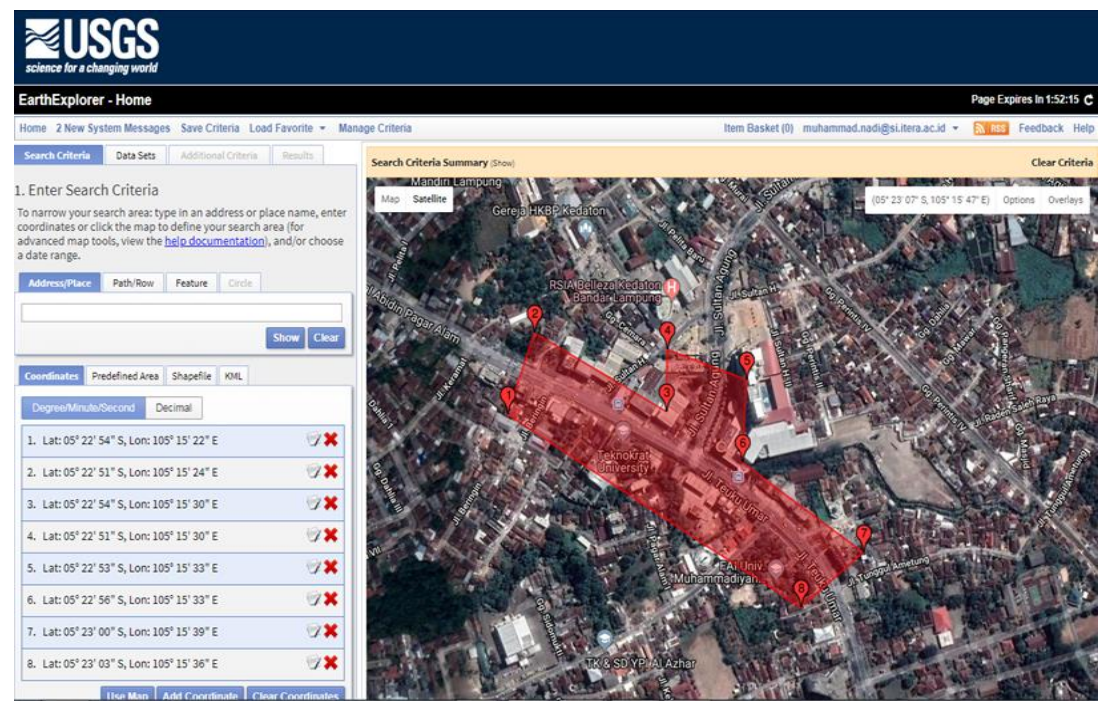

Figure 6. The location of analysis on flyover with

United States Geological Survey (USGS) maps

\section{Result and discussion}

We generated a pair of interferogram results from all possible pairs of PALSAR-2 images. The model that created by using InSAR technique, where the data we used in April 2017-May 2018. The interfrogram images is shown in figure 1 . In the interferogram processing scenario not all produce good results, it can be due to unwrapping error and atmospheric effects on the image itself. Furthermore we continue to process time series data for Bandar Lampung region by using SigmaSAR program.

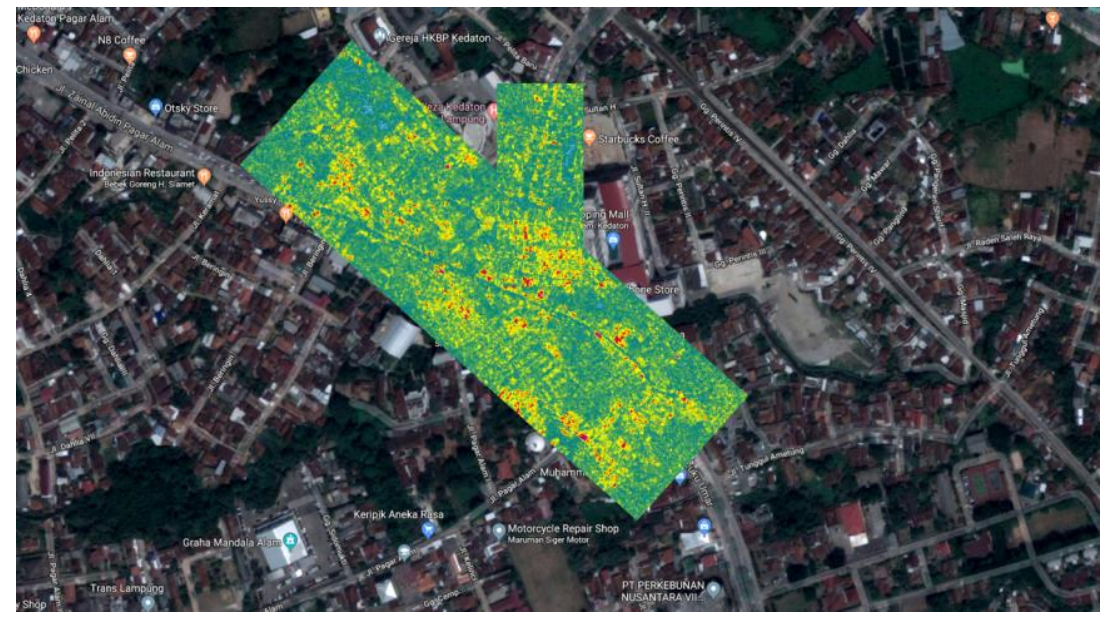

Figure 7. The result of InSAR analysis at study area

In the Differential InSAR method, we computed some interferograms scenario and the wrapped phase was corrected for spatially- uncorrelated look angle error and noise associated with the master image. After unwrapping stage and filtering spatially correlated noise then it can be calculated mean of velocity line-of-sight (LOS) and converted to height values. Results obtained based on correlation 
between Citra Radar images, yellow indicates no change, fig. 7 is the deformation of the results Processing InSAR in centimeters, where (red) is an indication of subsidence and (green) is an uplift (unit in centimeters).

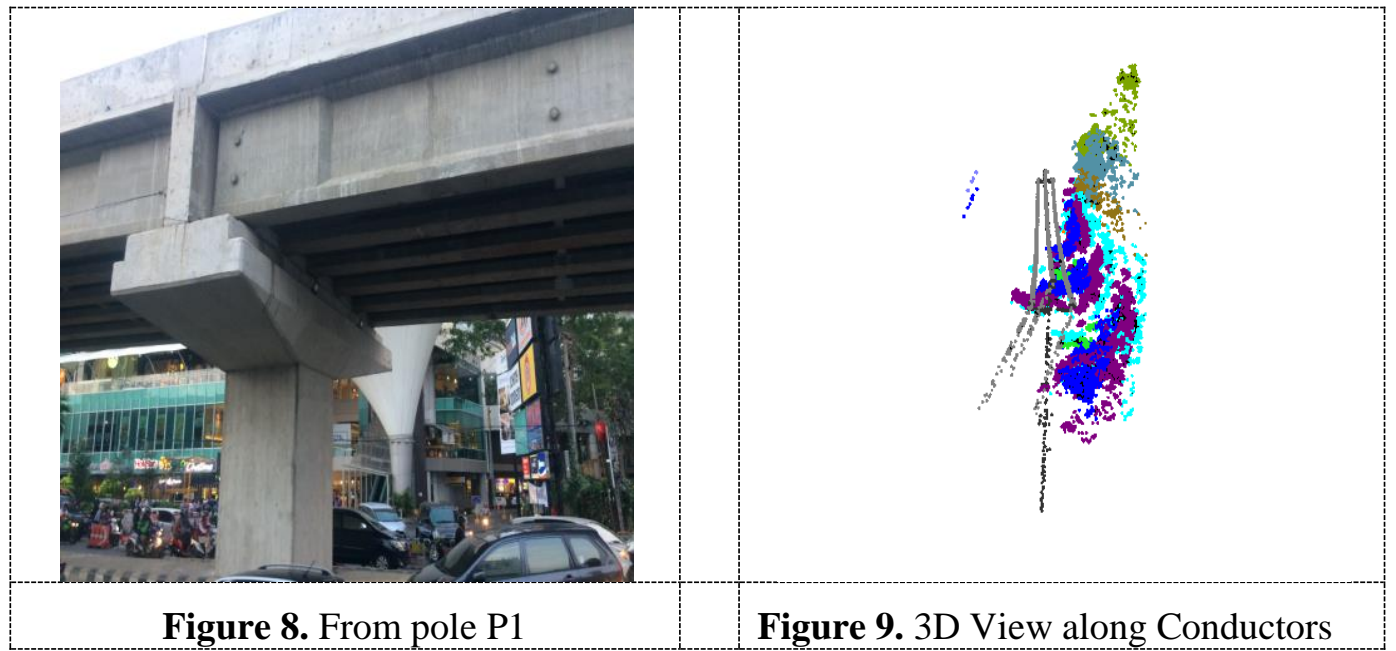

In Fig. 9 and Fig. 11, blue areas mean deformation occurred and uplifting respect to the mean deformation value. Taking into account that no uplifting is expected, we can consider that the light red areas are sinking slower than yellow which is located close to the bridge area. In other hand, we obtain the center of study area to be subsiding with a rate about $2.1 \mathrm{~cm}$. We can also see the estimated deformation field which is not as smooth as expected probably due to unwrapping errors when the interferogram lacks of correlation.

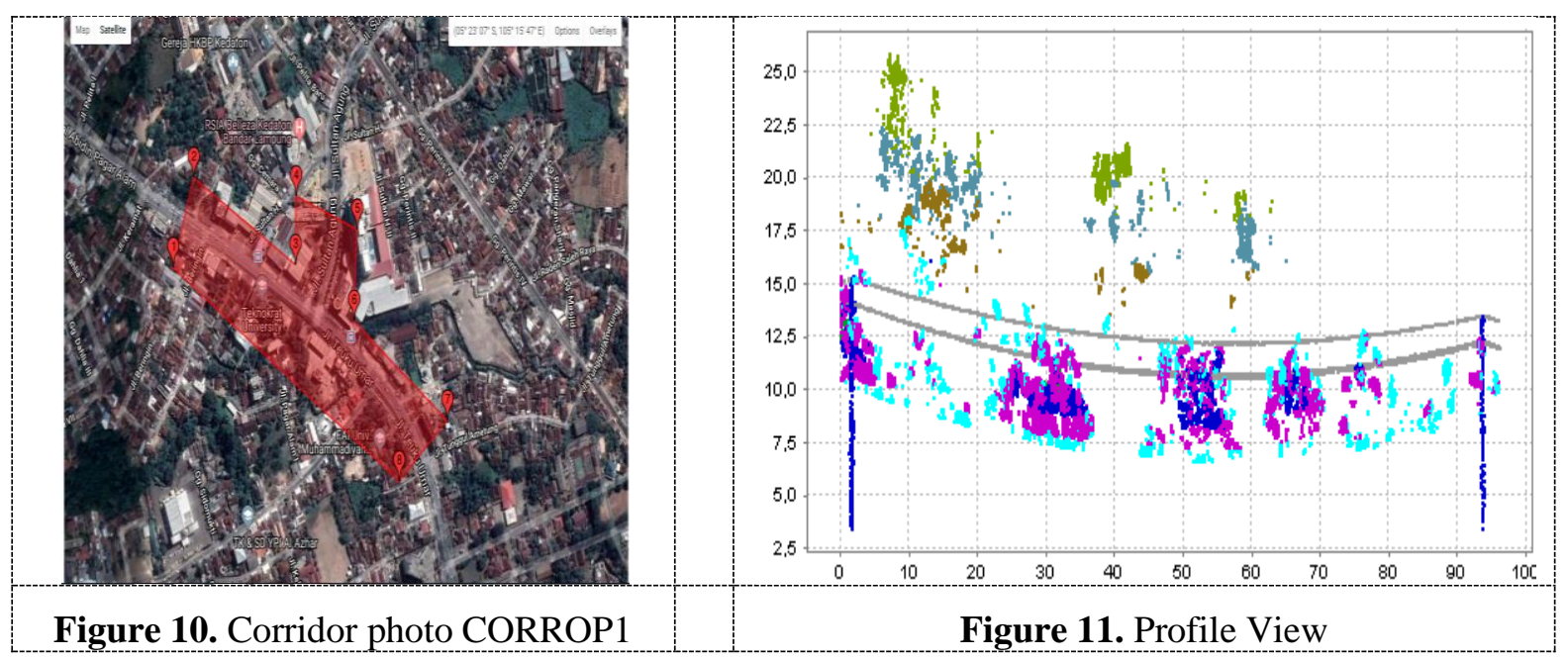

However, in the northern part (Sultan Agung Street) relatively small subsidence reach up to $0.7 \mathrm{~cm}$ and the southern part is lower reach up to $0.5 \mathrm{~cm}$. Generally the coherence value of ALOS-2 images is better than ALOS but the temporal resolution is opposite for the area in Indonesia, especially in Sumatera Island.

Crack depths varied greatly along their profiles. The real-world values represent multiple measurements in the interior of the crack and the largest measured depth model is also reported for comparison. As observed from these tables, millimeter and submillimeter accuracies can be achieved in controlled settings which promises the applicability of the proposed method. These measurements 
further show the proposed method for other types of defects and potholes on concrete and asphalt surfaces.

Table 3. Comparison of Real-World versus Model Crack Dimensions

\begin{tabular}{lcccc}
\hline & $\begin{array}{c}\text { Larger } \\
\text { crack } \\
\text { width }\end{array}$ & $\begin{array}{c}\text { Larger } \\
\text { crack } \\
\text { depth }\end{array}$ & $\begin{array}{c}\text { Smaller } \\
\text { crack } \\
\text { width }\end{array}$ & $\begin{array}{c}\text { Smaller } \\
\text { crack } \\
\text { depth }\end{array}$ \\
\hline Parameter & 10 & 6 & 4 & $\leq 2,5$ \\
Real-world dimension, $\zeta 1(\mathrm{~cm})$ & 9,85 & 6,06 & 3,91 & 2,52 \\
Model dimension, $\zeta 2(\mathrm{~cm})$ & 0,15 & 0,06 & 0,09 & 0,02 \\
Absolute error, $\Delta 1 / 4 \mathrm{j} \zeta 2-\zeta 1 \mathrm{j}(\mathrm{cm})$ & 1,5 & 1,07 & 2,2 & 0,8 \\
Relative error, $\delta 1 / 4 \Delta=\zeta 1(\%)$ & & & & \\
\hline
\end{tabular}

\section{Conclusion}

This work has presented an analysis of the ground subsidence phenomena in the urban area. The advanced differential InSAR technique is applied to this site using ALOS-2 PALSAR-2 images acquired from 2017 to 2018 . We identified a few locations in our study area. The average subsidence velocity map has been retrieved by D-InSAR technique processing to create deformation map. The urbanization and urban growth which have resulted in more groundwater extraction and infrastructure are mainly responsible for the subsidence in the study area.

Furthermore, this study aimed to examine the application of Close Range Photogrammetry technology with InSAR technology for the measurement of suspension bridge deformation. Survey of the current geometric data from the bridge or flyover structure is important for structural analysis and maintenance decision. By this study, simple measurement techniques were used on direct output point cloud format. The deformations were selected including the land subsidence, main bridge inclination and hanger inclination. We believe that the results can be used to further in order to identify possible causes of structural deformation and determine countermeasure to ensure structural analysis.

\section{References}

[1] Ahmed, M., Haas, C. T., and Haas, R. (2011). "Toward low-cost 3D automatic pavement distress surveying: The close range photogrammetry approach.” Can. J. Civ. Eng., 38(12), 1301-1313

[2] Bay, H., Ess, A., Tuytelaars, T., \& Van Gool, L. (2008). Speeded-Up Robust Features (SURF). Computer Vision and Image Understanding, 110, 346- 359. doi:10.1016/j.cviu.2007.09.014

[3] Brilakis, I., German, S., and Zhu, Z. (2011). "Visual pattern recognition models for remote sensing of civil infrastructure." J. Comput. Civ. Eng., 10.1061/(ASCE)CP.19435487.0000104, 388-393

[4] Chen, A. Y., Pe na-Mora, F., and Ouyang, Y. (2011). "A collaborative GIS framework to support equipment distribution for civil engineering disaster response operations." J. Autom. Constr., 20(5), 637-648

[5] Christen, R., Bergamini, A., and Motavalli, M. (2009). "High precision measurement of surface cracks using an optical system." Meas. Sci. Tech., 20(7), 077001

[6] Fujita, Y., and Hamamoto, Y. (2009). "A robust method for automatically detecting cracks on noisy concrete surfaces." Proc., Int. Conf. on Industrial, Engineering and Other Applications of Applied Intelligent Systems, Springer Publications, Tainan, Taiwan, 76-85

[7] Furukawa, Y., Curless, B., Seitz, S., and Szeliski, R. (2010). "Towards internet-scale multi-view stereo.” Proc., Computer Vision and Pattern Recognition, IEEE, San Francisco, CA, 14341441

[8] Golparvar-Fard, M., Thomas, J., Pẽna-Mora, F., and Savarese, S. (2010). “Remote assessment of pre-and post-disaster critical physical infrastructures using mobile workstation chariot 
and D4AR models." Proc., Int. Conf. on Computing in Civil and Building Engineering, Nottingham,U.K., 63-69

[9] Jahanshahi, M. R., and Masri, S. F. (2012). "Adaptive vision-based crack detection using 3D scene reconstruction for condition assessment of structures." J. Autom. Constr., 22, 567-576

[10] Jahanshahi, M. R., Masri, S. F., Padgett, C. W., and Sukhatme, G. S. (2013a). "An innovative methodology for detection and quantification of cracks through incorporation of depth perception." Mach. Vis. Appl., 24(2), 227-241

[11] Leutenegger, S., Chli, M., \& Siegwart, R. Y. (2011). BRISK: Binary robust invariant scalable keypoints. Paper presented at the computer vision (ICCV), IEEE International Conference, Barcelona, Spain

[12] Lowe, D. G. (2004). Distinctive image features from scale-invariant keypoints. International Journal of Computer Vision, 60, 91-110. doi:10.1023/B:VISI.0000029664.99615.94

[13] Yu, S. N., Jang, J. H., and Han, C. S. (2007). "Auto inspection system using a mobile robot for detecting concrete cracks in a tunnel." J. Autom. Constr., 16(3), 255-261

[14] Zhang, B., Lifang, L., Guiying, Y., and Tiantai, G. (2011). "A portable digital detection technique of building surface crack." Int. Symp. on Photoelectronic Detection and Imaging 2011: Sensor and Micromachined Optical Device Technologies, 819110-819116

[15] Zhang, Z., Guo, H., Nejat, G., and Huang, P. (2007). "Finding disaster victims: A sensory system for robot-assisted 3D mapping of urban search and rescue environments." IEEE Int. Conf. on Robotics and Automation, IEEE, New York, NY, 3889-3894

[16] Zhu, Z., and Brilakis, I. (2010). "Machine vision-based concrete surface quality assessment." J. Constr. Eng. Manage., 10.1061/(ASCE)CO .1943-7862.0000126, 210-218

[17] Zhu, Z., German, S., and Brilakis, I. (2011). "Visual retrieval of concrete crack properties for automated post-earthquake structural safety evaluation.” J. Autom. Constr., 20(7), 874-883

\section{Acknowledgments}

This research is funded by LP3 Institut Teknologi Sumatera, Lampung Indonesia. These financial supports are gratefully acknowledgments, so that authors can follow the event International Conference on Science Infrastructure Technology and Regional Development (ICoSITeR) on October 2018, in Lampung Indonesia. 